Tropical Journal of Pharmaceutical Research November 2021; 20 (11): 2381-2386

ISSN: $1596-5996$ (print); 1596-9827 (electronic) (C) Pharmacotherapy Group, Faculty of Pharmacy, University of Benin, Benin City, 300001 Nigeria.

\title{
Prevalence and predictors of seizure in patients with Alzheimer's disease at a tertiary care center in Riyadh, Saudi Arabia
}

\author{
Mohammed Alessa ${ }^{1 *}$, Shaden Alsugheir ${ }^{2,3}$, Nouf Almutairi' ${ }^{2,3}$, Abdulaziz \\ Alqahtani $^{2,3}$, Lina Alhumaid ${ }^{2,3}$, Rahaf Alqahtani ${ }^{2,4}$, Mohamed Eldigire Ahmed ${ }^{5}$ \\ ${ }^{1}$ Department of Clinical Pharmacy, College of Pharmacy, King Saud University, ${ }^{2}$ King Abdullah International Medical Research \\ Center, Ministry of the National Guard-Health Affairs, ${ }^{3}$ College of Medicine, King Saud Bin Abdulaziz University for Health \\ Sciences, ${ }^{4}$ College of Pharmacy, King Saud Bin Abdulaziz University for Health Sciences, Riyadh, Saudi Arabia, ${ }^{5}$ Applied \\ Statistics and Demography, University of Gezira, Wad Madani, Sudan
}

*For correspondence: Email: AlessaM@ksu.edu.sa; Tel: 00966-504106182

Sent for review: 23 December 2020

Revised accepted: 22 October 2021

\begin{abstract}
Purpose: To assess the prevalence and predictors of seizures in patients with Alzheimer's disease $(A D)$ at a Saudi tertiary hospital.

Methods: A retrospective, matched case-control study was conducted using the electronic medical records of patients with $A D$ who had an unprovoked seizure, from October 2015 to May 2018.

Results: Nineteen cases and 195 controls were identified. Statistically significant risk factors for an unprovoked seizure in patients diagnosed with $A D$ were hypertension $(p=0.001)$, autoimmune disease, stroke and TIA $(p=0.001)$. The multivariate logistic regression analysis identified hypertension $(O R=2.89 ; p=0.009)$ and autoimmune disease $(O R=19.6 ; p=0.045)$ as predictors of unprovoked seizure in $A D$ patients.

Conclusion: The occurrence of unprovoked seizures is more likely in severe cases of $A D$. In addition, the risk of seizure in patients with $A D$ increases with two co-morbid conditions, hypertension, and autoimmune disease. However, further studies are required to determine the underlying mechanism of the association between the two risk factors and $A D$.
\end{abstract}

Keywords: Alzheimer's disease, Seizure, Incidence, Predictors, Risk factor

\begin{abstract}
This is an Open Access article that uses a funding model which does not charge readers or their institutions for access and distributed under the terms of the Creative Commons Attribution License (http://creativecommons.org/licenses/by/4.0) and the Budapest Open Access Initiative (http://www.budapestopenaccessinitiative.org/read), which permit unrestricted use, distribution, and
\end{abstract} reproduction in any medium, provided the original work is properly credited.

Tropical Journal of Pharmaceutical Research is indexed by Science Citation Index (SciSearch), Scopus, International Pharmaceutical Abstract, Chemical Abstracts, Embase, Index Copernicus, EBSCO, African Index Medicus, JournalSeek, Journal Citation Reports/Science Edition, Directory of Open Access Journals (DOAJ), African Journal Online, Bioline International, Open-J-Gate and Pharmacy Abstracts

\section{INTRODUCTION}

Alzheimer's disease (AD) is one of the most common neurodegenerative disorders known among older patients [1]. In the United States, $A D$ is considered the sixth leading cause of mortality and 4.5 million patients are currently living with the disease [1]. In Saudi Arabia, there are no official statistics related to the prevalence of $A D$, but according to the Saudi Ministry of Health, the estimated number of $A D$ cases are at least 50,000, most of whom are women [2].

Several risk factors have been linked to $A D$ which include aging, smoking, cardiovascular diseases, stroke/transient ischemic attack (TIA), 
depression and family history of AD. In general, the clinical manifestations and symptoms of $A D$ develop slowly and are progressive [1]. The most prevalent clinical manifestations of $A D$ include memory loss, confusion, impaired judgment, language disturbance and agitation, while some other clinical manifestations are unusual which include seizures and Parkinsonian features [1].

Some previous studies have linked the late stages of $A D$ with unprovoked seizures $[3,4]$. It is estimated that the prevalence of seizures in $A D$ patients can reach up to $64 \%$ [5]. While the predictors of an unprovoked seizure in $A D$ patients include a younger age, severe dementia, focal epileptiform findings from an electroencephalogram (EEG) and an African American ethnicity [6]. Amatniek et al found that the risk of developing unprovoked seizure was 87-fold higher in younger patients, while it was more than 3-fold higher in the older group compared to the known AD age group [6]. In addition, there is a reported relationship between $A D$ and seizure disorders. Hauser et al found that patients with $A D$ are at higher risk of developing seizures and epilepsy [4].

The aim of this study was to determine the prevalence and predictors of seizures in $A D$ patients at King Abdulaziz Medical City (KAMC) in Riyadh, Saudi Arabia.

\section{METHODS}

\section{Study setting and participants}

A case-control study was conducted retrospectively among $A D$ patients who had seizures from October 2015 to May 2018 and were seen in the neurology clinic at KAMC, Ministry of National Guard-Health Affairs (MNGHA), in Riyadh, Saudi Arabia. Patients with the diagnosis of $A D$ and older than 18 years, either males or females, were included in the study. Patients who had a seizure provoked by medications, hypoglycemia or electrolyte imbalance were excluded from the study. Institutional Review Board (IRB) approval (no. H01R005) was obtained from King Abdullah International Medical Research Center (KAIMRC), Riyadh, Saudi Arabia. In addition, the STROBE guidelines were followed in this study [7].

\section{Identification of cases}

The KAIMRC database was used to identify the cases that will be matching the inclusion criteria at the neurology clinic. Using an electronic chart review approach, all $A D$ patients diagnosed with seizures from October 2015 to May 2018 were included $(n=214)$. Of the 214 identified $A D$ patients, only 19 patients matched our inclusion criteria. For each case, the electronic medical record was reviewed to ensure that the case is eligible for inclusion. Cases were matched to controls based on predictors of seizure.

\section{Seizure's predictors in AD Patients}

Seizure's predictors assessed based on published findings, seizure's epidemiological knowledge, and patient's characteristics. The evaluated potential predictors are listed in Table 1.

Table 1: Potential predictors based on previous studies [3,4,8-10]

\begin{tabular}{|c|c|}
\hline $\begin{array}{l}\text { Demographic } \\
\text { data }\end{array}$ & $\begin{array}{ll}- & \text { Age } \\
- & \text { Age at diagnosis of } A D \\
- & \text { Age at onset of seizure } \\
\text { - } & \text { Gender }\end{array}$ \\
\hline $\begin{array}{l}\text { Disease } \\
\text { duration }\end{array}$ & \\
\hline Seizure type & $\begin{array}{ll}\text { - } & \text { Simple } \\
\text { - } & \text { Generalized }\end{array}$ \\
\hline Severity of $A D$ & $\begin{array}{ll}\text { - } & \text { Mild } \\
\text { - } & \text { Moderate } \\
\text { - } & \text { Severe }\end{array}$ \\
\hline Co-morbidity & $\begin{array}{ll}\text { - } & \text { Hypertension } \\
\text { - } & \text { Congestive heart failure } \\
\text { (systemic lupus } \\
\text { erythematosus, celiac disease, } \\
\text { myasthenia gravis, rheumatoid } \\
\text { arthritis, psoriasis, } \\
\text { Hashimoto's encephalopathy, } \\
\text { neuromyelitis optica, multiple } \\
\text { sclerosis, and bullous } \\
\text { pemphigoid) } \\
\text { - Depression } \\
\text { - Stroke } \\
\text { - } \quad \text { MNS infection } \\
\text { Mental illness }\end{array}$ \\
\hline $\begin{array}{l}\text { Medications } \\
\text { Addiction }\end{array}$ & $\begin{array}{ll}\text { - } & \text { Anti-depressant medication } \\
\text { - } & \text { Alcohol } \\
\text { - } & \text { Drugs }\end{array}$ \\
\hline
\end{tabular}

CNS: Central nervous system

\section{Data collection and handling}

The data was retrieved from the Best-Care System, an electronic medical records system used in Ministry of National Guard - Health Affairs (MNGHA), under the supervision of a neurology consultant and a statistician. Medical record information was collected using a prepared data collection form. The data collectors used the approved data collection form to ensure consistency of coding. The supervisors 
reviewed the data collected by the data collectors to ensure the accuracy of the data.

\section{Statistical analysis}

\section{Data cleaning}

The raw data was audited and cleaned prior to the statistical analysis. In order to accomplish this task, all interval variables were checked and summarized in terms of maximum and minimum values. Minimum and maximum values were checked and compared against a possible maximum and minimum value of each variable and variables with implausible values were flagged. A similar process was done to the categorical variables to identify any potential anomalies (miscodes) using a frequency analysis.

\section{Data analysis}

Descriptive statistical analyses were performed. Continuous variables were summarized as mean $\pm \mathrm{SD}$ and median (range). Proportions were used for categorical variables. In addition, demographic and clinical information were summarized in frequency tables. The $95 \%$ confidence interval $(\mathrm{Cl})$ was used. The binary logistic regression model was used to estimate the regression equation between the outcome variable (AD) and selected significant explanatory variables, namely hypertension and auto-immune disease. The binary logistic regression model takes the formula:

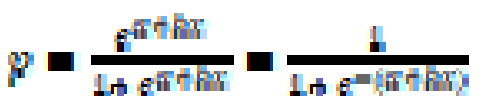

A $P$ value of less than $5 \%$ was considered as statistically significant. All statistical analyses were performed using SPSS 21.0 (Release 21.0.0.0, IBM, USA).

\section{RESULTS}

The total number of identified $A D$ patients was 214 patients. Patients' age ranged from 56 years to 111 years. Almost half of the sample $(46 \%, n$ $=98$ ) were males. In addition, majority of the patients $(98 \%)$ were Saudis.

\section{Prevalence of seizures}

Out of 214 patients, 19 (8.9\%) of AD patients developed an unprovoked seizure $(95 \% \mathrm{Cl}, 8.2$ 9.5). Males constituted $47.4 \%(n=9)$. The mean age at diagnosis of $A D$ was $73.2 \pm 8.8$ years (range $=53$ to 88 years), and the mean age at seizure onset was $74.3 \pm 13.8$ years (range $=57$ - 91years). The mean duration from the AD diagnosis to the occurrence of the seizure was $19 \pm 12.8$ months (range $=6-60$ months). Generalized tonic-clonic seizure was the most prevalent type of seizure accounting for $94.7 \%$ $(n=18)$ of the patients, and one patient $(5.2 \%)$ had a focal seizure.

Table 2: Characteristics of AD patients with and without unprovoked seizures

\begin{tabular}{lccc}
\hline Characteristics & $\begin{array}{c}\text { AD with seizures } \\
(\mathbf{n}=\mathbf{1 9})\end{array}$ & $\begin{array}{c}\text { AD without seizure } \\
(\mathbf{n}=\mathbf{1 9 5})\end{array}$ & $\boldsymbol{P}$-value \\
\hline Male & 9 & 89 & 0.885 \\
Mean age years (SD) & $78.2+8.8$ & $75.1 \pm 8.9$ & 0.140 \\
Mean age at diagnosis of AD & $73.2 \pm 8.8$ & $73.1 \pm 9.5$ & 0.098 \\
(SD) & $19 \pm 12.8$ & $18.2 \pm 10.6$ & 0.444 \\
Mean duration of AD months & & & \\
(SD) & 0 & 25 & 0.001 \\
Severity of AD & 3 & 31 & 0.155 \\
Mild & 16 & 42 & 0.717 \\
Moderate & 0 & 97 & 0.001 \\
Severe & 5 & 3 & 0.776 \\
Unknown & 1 & 3 & \\
Risk factors & 15 & 80 & 0.040 \\
Head Trauma & 2 & 15 & 0.060 \\
History of Epilepsy & & & 0.710 \\
Hypertension & 1 & 11 & 0.001 \\
Congestive Heart Disease & 3 & 14 & 29 \\
& 6 & 28 & \\
Auto-immune Disease & 9 & & \\
Use Anti-depressant & & & \\
Mental Disease & & & \\
Stroke & & & \\
\hline
\end{tabular}


Table 3: Positive risk factors by seizure status

\begin{tabular}{|c|c|c|c|}
\hline Factor & $\begin{array}{c}\text { AD with seizures } \\
n=19 \\
n(\%) \\
\end{array}$ & $\begin{array}{c}\text { AD without seizure } \\
n=195 \\
n(\%)\end{array}$ & OR $(95 \% \mathrm{Cl})$ \\
\hline History of epilepsy & $5(26.3)$ & $3(1.5)$ & $22.8(4.9-105.6)$ \\
\hline Head Trauma & $1(5.3)$ & $3(1.5)$ & $3.5(0.35-35.9)$ \\
\hline Hypertension & $15(78.9)$ & $80(41.0)$ & $5.4(1.7-16.8)$ \\
\hline Congestive heart disease & $2(10.5)$ & $15(7.9)$ & $1.4(0.29-6.7)$ \\
\hline Auto-immune disease & $1(5.3)$ & $1(0.51)$ & $10.8(0.65-179.7)$ \\
\hline Use anti-depressant & $3(15.8)$ & $14(7.2)$ & $2.4(0.63-9.3)$ \\
\hline Mental disease & $6(31.6)$ & $29(14.9)$ & $2.7(0.92-7.5)$ \\
\hline Stroke & $9(47.4)$ & $28(14.4)$ & $0.4(2.0-14.4)$ \\
\hline
\end{tabular}

Table 4: Binary logistic regression of seizure predictors

\begin{tabular}{lccc}
\hline Variable & $\boldsymbol{\beta}$ & $\boldsymbol{P}$-value & OR \\
\hline Hypertension & -1.061 & 0.009 & 2.89 \\
Auto-immune disease & 2.983 & 0.045 & 19.6 \\
\hline
\end{tabular}

The analysis included 19 patients with $A D$ and an incidental diagnosis of seizures, and 195 patients with $A D$ diagnosis but without seizures. Characteristics of matched cases reported in Table 2. The majority of the patients $(84.0 \%, n=$ $16)$ had severe $A D$, and 3 patients $(15.8 \%)$ were classified as moderate $A D$, suggesting that the risk of a seizure is more likely to occur in severe cases of the disease.

The potential risks of developing a seizure in AD patients include hypertension, stroke or transient ischemic attack (TIA), head injury, current use of psychotropic medications, congestive heart disease and auto-immune disease. The confounders were analyzed using bi-variant analysis. Statistically significant risk factors of developing a seizure in $A D$ patients were hypertension ( $p=0.001)$, autoimmune disease $(p$ $=0.040)$ as well as stroke and TIA $(p=0.001)$ (Table 3).

The multivariate logistic regression analysis indicated hypertension (OR $=2.89 ; p=0.009)$ and autoimmune disease (OR $=19.6 ; p=0.045)$ as predictors of seizure in AD patients (Table 4).

\section{DISCUSSION}

Earlier studies reported a higher risk of unprovoked seizures among patients with AD [4$6]$. In the current study, unprovoked seizure was reported in 19 of $214 \mathrm{AD}$ patients with an incidence rate of $8.9 \%$. McAreavey et al conducted a study among $A D$ patients, and found that out of 208 AD patients, unprovoked seizures were reported among 19 of them (9.1 $\%$ ) [11]. In addition, Cheng et al reported that 44 of $937 \mathrm{AD}$ patients $(4.7 \%)$ developed unprovoked seizures during the 10 - year followup period [12].
In terms of the type of seizure, different types are reported in literature $[4,6]$. In the current study, the majority $(94.7 \%, n=18)$ were classified as generalized seizures. Similarly, Mendez et al reported generalized seizures in majority of $A D$ cases $(90 \%)$ [13]. In contrast, Rao et al reported that $72 \%$ of the seizures were complex partial seizures [9]. In addition, Mendez et al indicated that the onset of the seizures tends to occur during the later stages of the disease, on average 6.8 years after the diagnosis of $A D$ [13]. In contrast, in the current study, the average seizure onset was 1.5 years after the diagnosis of the disease.

Furthermore, many studies suggested that the severe form of $A D$ had a higher risk of seizure with frequencies ranging from $9 \%$ to $64 \%[13$ 15]. In our study, $84 \%$ of $A D$ patients with seizure had a severe type of $A D$. In addition, hypertension also indicated an increased risk of seizure in $A D$ patients. However, Bernardi et al did not find hypertension as a predictor of seizure in $A D$ patients but considered it as a protective factor against seizure occurrence [16].

In addition, many studies have reported that a younger age at diagnosis of $A D$ was a significant risk factor for developing seizures [6,8-18]. However, in the current study, younger age was not a risk factor for developing seizure in $A D$ patients. This could be attributed to the lack of proper documentation as many of the files lacked the date of the initial diagnosis.

\section{Limitations of the study}

We acknowledge that our study has some limitations. This is a single center study. The research results may have been more generalizable if it was conducted in multiple centers with a larger population. In addition, due 
to the retrospective study design, no follow up data of patients were obtained. Furthermore, the data were collected from electronic medical records with some missing data; for example, the Mini-Mental State Examination scores (MMSE), Clinical Dementia Rating (CDR), Electroencephalogram (EEG), and the classification of $A D$.

\section{CONCLUSION}

The results of this study show that the occurrence of seizure in patients with $A D$ is more likely in severe cases of the disease. In addition, the risk of seizure in patients with $A D$ increases with two co-morbid conditions, namely, hypertension, and autoimmune disease. Further studies are required to determine the underlying mechanism of the association between the risk factors for seizures and $A D$.

\section{DECLARATIONS}

\section{Conflict of Interest}

No conflict of interest associated with this work.

\section{Contribution of Authors}

The authors declare that this work was done by the authors named in this article and all liabilities pertaining to claims relating to the content of this article will be borne by them.

\section{Open Access}

This is an Open Access article that uses a funding model which does not charge readers or their institutions for access and distributed under the terms of the Creative Commons Attribution License (http://creativecommons.org/licenses/by/ 4.0) and the Budapest Open Access Initiative (http://www.budapestopenaccessinitiative.org/rea d), which permit unrestricted use, distribution, and reproduction in any medium, provided the original work is properly credited.

\section{REFERENCES}

1. Alzheimer disease. National Center for Biotechnology Information (US). Genes and Disease. 1998 [cited 2018 May 25]. Available from: https://www.ncbi.nlm.nih.gov/ books/NBK22170/.

2. World Alzheimer's Day. Health Days. 2013 [cited 2018 May 26]. Available at: https://www.moh.gov.sa/en/Health Awareness/healthDay/2013/Pages/HealthDay-019.aspx.

3. Hesdorffer, DC, Hauser WA, Annegers JF, Kokmen E, Rocca WA. Dementia and adult-onset unprovoked seizures. Neurol 1996; 46(3): 727-730
4. Hauser WA, Morris ML, Heston LL, Anderson VE. Seizures and myoclonus in patients with Alzheimer's disease. Neurol 1986; 36(9): 1226-1230.

5. Friedman D, Honig LS, Scarmeas $N$. Seizures and epilepsy in Alzheimer's disease. CNS Neurosci Ther 2012; 18(4): 285-294.

6. Amatniek JC, Hauser WA, DelCastillo-Castaneda C, Jacobs DM, Marder K, Bell K, Albert M, Brandt J, Stern $Y$. Incidence and Predictors of Seizures in Patients with Alzheimer's Disease. Epilepsia 2006; 47(5): 867-872.

7. Von Elm E, Altman DG, Egger M, Pocock SJ, Gøtzsche PC, Vandenbroucke JP; STROBE Initiative. The Strengthening the Reporting of Observational Studies in Epidemiology (STROBE) statement: guidelines for reporting observational studies. Clin Epidemiol 2008; 61(4): 344-349

8. Daniel FM, Lawrence SH, Nikolaos S. Seizures and Epilepsy in Alzheimer's Disease. CNS Neurosci Ther 2012; 18(4): 285-294.

9. Rao SC, Dove G, Cascino GD, Petersen RC. Recurrent seizures in patients with dementia: Frequency, seizure types, and treatment outcome. Epilepsy Behav 2009; 14(1): 118-120.

10. Plassman BL, Langa KM, Fisher GG, Heeringa SG, Weir $D R$, Ofstedal MB, Burke JR, Hurd MD, Potter GG, Rodgers WL, et al. Prevalence of Dementia in the United States: the Aging, Demographics, and Memory Study. Neuroepidemiol 2007; 29(1-2): 125-132.

11. McAreavey MJ, Ballinger BR, Fenton GW. Epileptic seizures in elderly patients with dementia. Epilepsia 1992; 33(4): 657-660.

12. Cheng CH, Liu CJ, Ou SM, Yeh CM, Chen TJ, Lin YY, Wang SJ. Incidence and risk of seizures in Alzheimer's disease: A nationwide population-based cohort study. Epilepsy Res 2015; 115, 63-66.

13. Mendez MF, Catanzaro P, Doss RC, ARguello R, Frey $W H$ II. Seizures in Alzheimer's disease: Clinicopathologic study. J Geriatr Psychiatry Neurol 1994; 7(4): 230-233.

14. Yaffe K, Falvey C, Harris TB, Newman A, Satterfield S, Koster A, Ayonayon $H$, Simonsick $E$. Effect of Socioeconomic Disparities on Incidence of Dementia among Biracial Older Adults: Prospective Study. BMJ 2013; 347: f7051.

15. Risse SC, Lampe TH, Bird TD, Nochlin D, Sumi SM, Keenan T, Cubberley L, Peskind E, Raskind MA. Myoclonus, seizures, and paratonia in Alzheimer disease. Alzheimer Dis Assoc Disord 1990; 4(4): 217225.

16. Bernardi S, Scaldaferri $N$, Vanacore $N$, Trebbastoni $A$, Francia $A$, D'Amico $A$, Prencipe $M$. Seizures in Alzheimer's disease: a retrospective study of a cohort of outpatients. Epileptic Disorders 2010; 12(1): 16-21.

17. Volicer L, Smith S, Volicer BJ. Effect of seizures on progression of dementia of the Alzheimer type. Dementia 1995; 6(5): 258-263.

18. Jacobs $D$, Sano M, Marder K, Bell K, Bylsma F, Lafleche G, Albert M, Brandt J, Stern Y. Age at onset of Trop J Pharm Res, November 2021; 20(11): 2385 
Alessa et al

Alzheimer's disease: relation to pattern of cognitive dysfunction and rate of decline. Neurol 1994; 44(7): 